\title{
Dissolution of cholesterol gall stones using methyltertbutyl ether: a safe effective treatment
}

\author{
J McNulty, A Chua, J Keating, S Ah-Kion, D G Weir, P W N Keeling
}

\begin{abstract}
Methyltertbutyl ether (MTBE) administered by percutaneous transhepatic catheter rapidly dissolves radiolucent cholesterol gall bladder stones. However, complete dissolution and clearance of non-cholesterol debris is essential to prevent recurrence. In this study we analysed 25 consecutive patients with reference to efficacy and recurrence based on the presence or absence of non-cholesterol stone fragments after dissolution. Placement of the catheter was successful in 24 patients, one patient requiring cholecystectomy for bile peritonitis. MTBE was infused and aspirated continuously, four to six cycles per minute, resulting in rapid stone dissolution (median six hours; range 4-23 hours for solitary stones and median seven hours, range 4-30 hours for multiple stones). In 18 patients who had complete dissolution, four (22\%) had recurrent stones within six to 18 months. Five patients had residual debris which failed to clear completely despite bile acid treatment. One patient with an incomplete rim of calcium in a large stone did not respond to MTBE treatment. A further patient required cholecystectomy for symptomatic recurrence. There were no serious side effects observed. MTBE treatment is a rapid, safe, and effective treatment for patients who refuse surgery or who for medical reasons cannot undergo cholecystectomy. The results of this study confirm that complete dissolution of all fragments is essential and may prevent recurrence.
\end{abstract}

In the West cholesterol stones account for over $90 \%$ of gall bladder calculi found at cholecystectomy. Most of these stones contain less than 5\% calcium, which makes them amenable to contact dissolution with solvents such as mono-octanoin and methyltertbutyl ether (MTBE). ${ }^{1-7}$ Surgery is still the standard procedure for gall bladder stones. However, alternative methods for removing gall stones from the gall bladder and biliary tree are now available, thus avoiding the risks of general anaesthesia and surgery. Bile acids as a primary treatment for cholesterol calculi are unsatisfactory. ${ }^{8-10}$ Furthermore, acquired gall stone calcification can develop in over $10 \%$ of patients after prolonged ursodeoxycholic acid treatment." An alternative method is to shatter the stone with lithotripsy, a technique also used for calcified stones. ${ }^{12}$ This modality used in combination with MTBE or oral bile acids may prove to be a rapid non-invasive treatment for calcified as well as uncalcified cholesterol stones. ${ }^{14}$ Fragmentation of stones allows the solvent access to the cholesterol component of the stone.
The Mayo Clinic has shown that cholesterol stones can be dissolved rapidly with MTBE in most cases. They treated a large group of patients with symptomatic cholesterol gall stones with a $95 \%$ success rate. $^{15}$ Despite these excellent results, this technique required testing by other centres before receiving widespread approval. We have set up a dissolution programme and report the results of the first 25 patients treated.

\section{Patients and methods}

Between January 1989 and July 199025 symptomatic patients were selected for contact dissolution. Symptoms included previous episodes of acute cholangitis or biliary colic, or both. Twenty patients refused surgery and five were medically unfit for cholecystectomy due to obesity, chronic obstructive airways disease, and previous coronary artery bypass surgery. Gall stones were diagnosed by abdominal ultrasonography. All patients had a functioning gall bladder on oral cholecystography. Computed tomography of the gall bladder was performed in 22 patients: no appreciable calcification was detectable in 18 , a core of calcium was seen in three, and an incomplete rim of calcification was noted in one. In the three patients above, calcification was not detected on the plain films of the abdomen.

Patients were sedated with intravenous pethidine $80 \mathrm{mg}$ (50-100 $\mathrm{mg}$ ) and midazolam $3 \mathrm{mg}$ (1-4 mg) (median and range) before placement of a Thistle pig-tail catheter. The catheter was inserted percutaneously under fluoroscopy through the right lobe of the liver into the gall bladder and coiled around the gall stones. ${ }^{15}$ Fluoroscopic time varied from two to seven minutes, with an average screening time of 4.5 minutes. After catheter cholecystography confirmed no extravasation, the gall bladder was drained of bile and contrast medium. Continuous infusion and aspiration of MTBE was started through the catheter using a glass syringe. MTBE was delivered to the gall bladder from a $20 \mathrm{ml}$ glass syrine via a 5 French $(1.7 \mathrm{~mm}$ diameter) Thistle pigtail catheter. The volume of MTBE used was 2-10 $\mathrm{ml}$. This treatment volume was determined at fluoroscopy and found to be less than the volume of radio-opaque contrast medium required to overflow into the cystic duct. Volume changes may occur during dissolution, perhaps related to gall bladder wall oedema or spasm. Consequently, catheter cholecystography was performed at regular intervals after starting treatment and radiographs were taken to assess gall stone diameter. The maximum dissolution time for any one day was six hours (two periods of three hours with a two hour interval). Dissolution was discontinued 


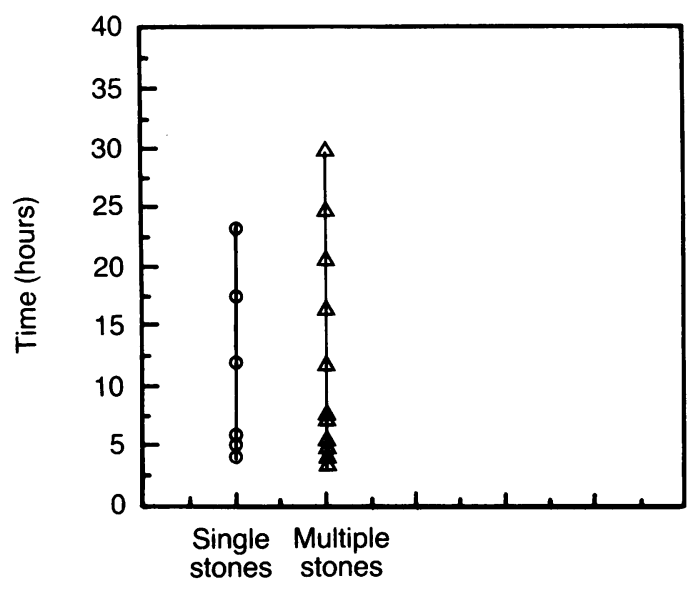

Figure 1: Time taken to dissolve stones for each patient comparing patients with solitary and multiple stomes.

if the physician found an odour of MTBE from the patient's breath or if the patient experienced pain, emesis, or became sedated. The capacity of the gall bladder and the volume required to spill into the cystic duct were analysed by catheter
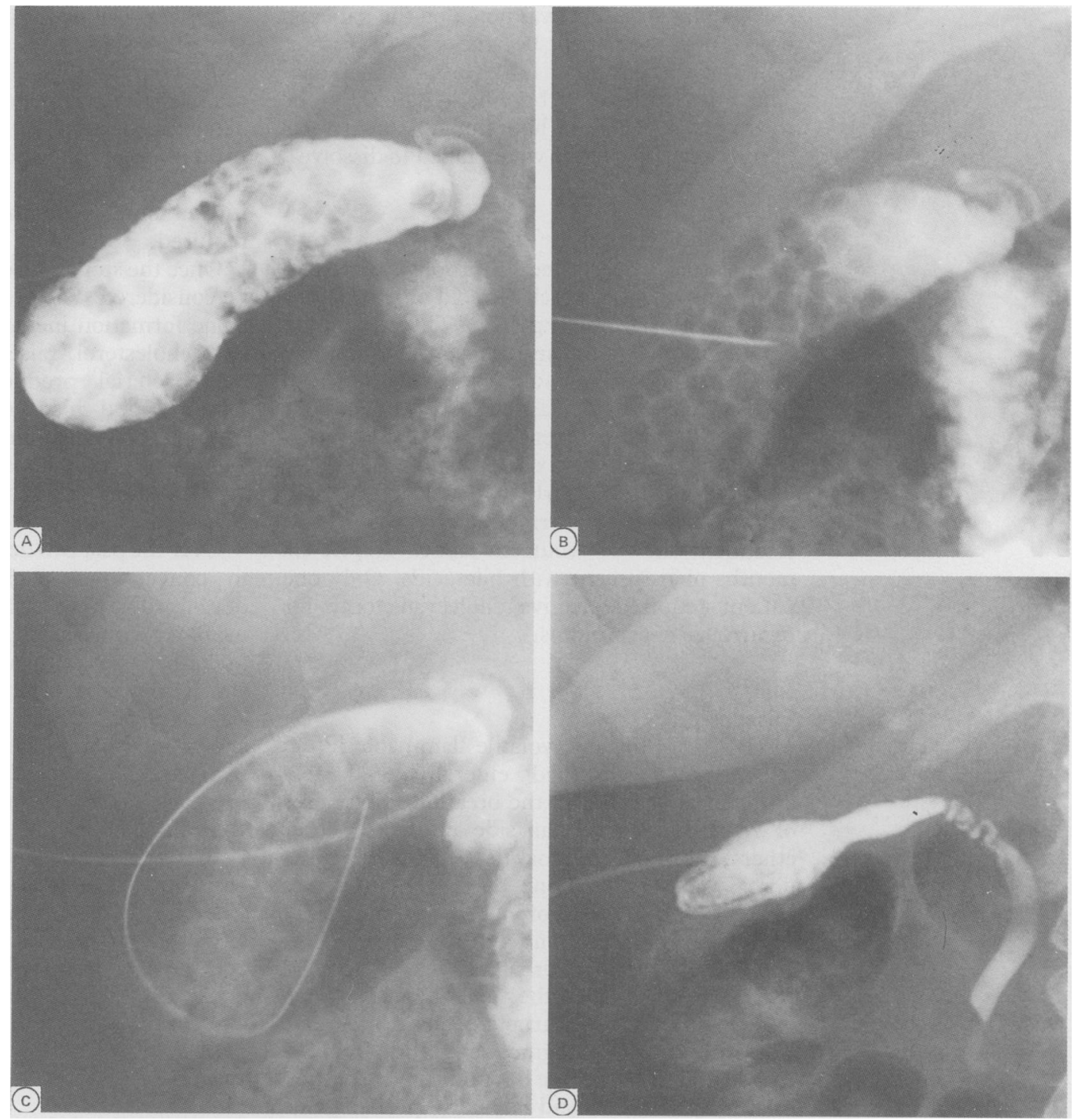

cholecystography at regular intervals as gall bladder oedema or repositioning of the catheter may critically alter this volume.

\section{Results}

Twenty five patients whose ages ranged from 24 to 83 years (median 52 years) were selected for treatment. Gall stone dissolution was rapid. For solitary stones the median dissolution time was six hours (range 4-23 hours) and for multiple stones seven hours (range 4-30 hours) (Fig 1). Of 25 patients treated, 18 had complete stone dissolution, five had residual debris with an acoustic shadow on ultrasound, the calcified rim of one patient's gall stone failed to dissolve, and a further patient developed bile peritonitis during catheter placement and required emergency surgery. MTBE was infused and aspirated manually through a Thistle catheter using a glass syringe (Fig 2). Because of the formation of a variable amount of emulsion in the aspirate which contains bile, gall stone fragments, and MTBE, the estimate of completeness of MTBE retrieved is imperfect and must be supplemented

Figure 2: Opacified gall bladder with $(A)$ multiple radiolucent calculi; $(B)$ catheter needle being placed in gall bladder; $(C)$ guidewire inserted and coiled in the gall bladder over which a Thistle catheter is being inserted; $(D)$ gall bladder free of calculi after four hours of dissolution treatment with methyltertbutyl ether. 
by careful clinical monitoring of the patients, especially with regard to sedative effects and the odour of MTBE on the patient's breath.

\section{COMPLICATIONS}

Treatment was well tolerated. However, two patients developed obstructive jaundice, one of whom developed a transient obstructive jaundice (serum bilirubin $125 \mu \mathrm{mol} / \mathrm{l}$, normal $<20$ $\mu \mathrm{mol} / \mathrm{l})$ four months after dissolution treatment, but at endoscopic retrograde cholangiopancreatography both the gall bladder and common bile duct were free of stones. A second patient developed an episode of cholangitis during dissolution treatment and at endoscopic retrograde cholangiopancreatography a stone fragment was removed from the lower end of the common bile duct. A further two patients developed cholangitis during dissolution treatment which responded to parenteral antibiotic treatment. No appreciable change in liver function tests occurred in the remaining patients during dissolution treatment, nor was there evidence of intravascular haemolysis. Abdominal pain treated with pethidine occurred during treatment in 10 patients. Solvent extravasation was not detected. If an adour of MTBE was noted on the patient's breath or if the patient became sedated dissolution was discontinued for that particular day. The only patient to become sedated by the treatment received 23 hours of treatment for a partially calcified stone which failed to dissolve.

\section{FOLLOW UP ASSESSMENT}

All patients were started on prophylactic treatment with chenodeoxycholic acid or ursodeoxycholic acid (10 mg kg/day). Three monthly abdominal ultrasound and oral cholecystography were performed on all patients. Fourteen patients had no evidence of calculi, while in four patients stone recurrence was noted during follow up of between six and 18 months. Follow up scans of the five patients with small stone fragments noted on ultrasound after dissolution treatment showed recurrent stones despite six months of treatment with bile acids. Only one patient required elective cholecystectomy for recurrence of symptoms.

\section{Discussion}

MTBE is a pungent, volatile flammable liquid which when absorbed enterally is largely excreted unchanged in the breath. ${ }^{15}$ High doses of MTBE have similar side effects to other ethers, causing respiratory depression, but at the doses used in gall stone dissolution it is less toxic. ${ }^{15-18}$ The results of our study show that MTBE can safely and effectively dissolve cholesterol gall bladder stones when instilled percutaneously into the gall bladder. Two patients developed obstructive jaundice. In one it was due to a stone fragment migrating from the gall bladder into the bile duct during dissolution treatment. In the second case it was probably due to the passage of biliary sludge which caused transient jaundice. In the Mayo Clinic series $10 \%$ of the patients had symptoms related to gall stone debris. In our series only one of the nine patients with stone recurrence was symptomatic. Pain was a feature in 10 patients during but not after dissolution. In the Mayo Clinic series $32 \%$ had a gastrointestinal upset and pain, but this was not a problem during the dissolution period. However, $16 \%$ of patients required analgesia after catheter removal. ${ }^{\text {is }}$

Catheterisation of the gall bladder by percutaneous transhepatic approach via the gall bladder fossa is a safe procedure. Only one of our patients developed appreciable biliary extravasation. If there is a leak from the gall bladder, this will occur extraperitoneally and will tamponade between the gall bladder and the undersurface of the liver. However, when the gall bladder is mobile and not attached to the liver undersurface, catheterisation may be more difficult. ${ }^{\text {is }}$

Estimation of gall bladder volume prevents overfilling and spillage of MTBE from the gall bladder into the biliary system and duodenum. In addition, treatment with MTBE causes oedema and perhaps spasm of the gall bladder wall and may cause appreciable changes in gall bladder capacity. Therefore serial estimates of gall bladder volume ought to be performed during prolonged treatment.

Patient selection is of paramount importance. It is necessary to have a cooperative patient with a functioning gall bladder containing noncalcified stone(s). Computed tomography may detect calcification of the gall stone not found on plain film of the abdomen and may help to distinguish rim from core calcium. However, further studies on the value of scanning are required.

Once the stones are dissolved recurrence must be considered. Factors which predispose to gall stone formation include supersaturation of bile with cholesterol, raised glycoprotein synthesis, and bacterial production of lysolecithin. ${ }^{18-22}$ Dowling and his group observed that nonsteroidal anti-inflammatory drugs may prevent gall stone recurrence probably by reducing glycoprotein synthesis. ${ }^{23}$ Bile acid therapy will also prevent gall stone recurrence. ${ }^{24-27}$

Over the past two decades alternative methods to conventional cholecystectomy have been developed. These include minicholecystectomy using a $5 \mathrm{~cm}$ incision, which may reduce postoperative pain with a better cosmetic result. ${ }^{28}$ Further refinements include laparoscopic cholecystectomy ${ }^{29} 30$ where preliminary results have shown minimal scarring, reduced postoperative pain, and a shortened hospital stay. However, previous upper abdominal surgery may be a contraindication.

Extracorporeal shock wave lithotripsy may only cause fragmentation of gall bladder stone(s). Therefore bile acid treatment may be required to clear stone fragments. ${ }^{31}{ }^{32}$ Consequently, MTBE contact dissolution will obviously compete with cholecystectomy as a method of treatment of cholesterol gall bladder stones, particularly in patients with a medical contraindication to surgery.

1 Van der Linden W, Nakayama F. Gallstone disease in Sweden versus Japan. Clinical and etiological aspects. Am $\mathcal{F}$ Surg 1973; 125: 267-72. 
2 Karran S, Lane RHS. Calculous disease and cholecystitis. In: Wright R, Alberti KGMM, Karran S, Millward-Sadler GH, eds. Liver and biliary disease. London: Saunders, 1979: eds. Liver

3 Hellstern A, Leuschner M, Fisher H, Lazarovici D, Gullutuna $\mathrm{S}$, Kurtz W, et al. Percutantranshepatische lyse von S, Kurtz W, et al. Percutantranshepatische lyse von Wochenschr 1988; 113: 506-10.

4 Tritapepe R, DiPadova C, Pozzoli M, Rovagnati P, Montorsi $W$. The treatment of retained biliary stones with monooctanoin: report of 16 patients. Am $\mathcal{F}$ Gastroenterol 1984; 79: $710-4$.

5 Mack E, Patzer Em, Crummy AB, Hofmann AF, Babayan VK. Retained biliary tract stones. Non-surgical treatment with Capmul 8210, a new cholesterol gallstone dissolution agent. Arch Surg 1981; 110: 341-4.

6 Allen MJ, Borody TJ, Bugliosi TF, May GR, La Russo NF, Thistle JL. Rapid dissolution of gallstones with methyl tertThistle JL. Rapid dissolution of gallstones with
butyl ether. $N$ Engl F Med 1985; 312: 217-20.

7 Keating J, O'Reilly E, Burke P, Monson J, Corrigan OI, Stephens $\mathrm{R}$, et al. Mono-octanoin significantly inhibits invivo gallstone dissolution by methyl tert-butyl ether, an experimental study. Gastroenterology 1988; 94: A553.

8 Maton PN, Iser JH, Reuben A, Saxton HM, Murphy GM, Dowling RH. Outcome of chenodeoxy cholic acid (CDCA) treatment in 125 patients with radiolucent gallstones. Medicine 1982; 61: 85-96.

9 Schoenfield LJ, Lachin JM. The Steering Committee. The National Cooperative Gallstone Study. Ann Intern Med 1981; 95: 257-82.

10 Podda M, Zuin M, Battezzati PM, Ghezzi C, de Fazio C Dioguardi ML. Efficacy and safety of a combination of chenodeoxycholic acid and ursodeoxycholic acid for gallchenodeoxycholic acid and ursodeoxycholic acid for gall-
stone dissolution: a comparison with ursodeoxycholic acid stone dissolution: a comparison with urso
alone. Gastroenterology 1989; 96: 222-9.

11 Gleeson D, Ruppin DC, Saunders A, Murphy GM, Dowling RH. Final outcome of ursodeoxycholic acid treatment in 126 patients with radiolucent gallstones. $Q \mathcal{F}$ Med 1990; 279: 711-29.

12 Sauerbruch T, Delius M, Paumgartner G, et al. Fragmentation of gallstones by extracorporeal shock waves. $N \mathrm{Engl} \mathcal{F}$ Med 1986; 314: 818-22.

13 Paumgartner, G. Fragmentation of gallstones by extracorporeal shock waves. Semin Liver Dis 1987; 7: 317-21.

14 Peine CJ, Petersen BT, Williams HJ, Bender CE, Patterson DE, Segura JW, et al. Extracorporeal shock wave lithotripsy and methyl tert-butyl ether for partially calcified gallstones. Gastroenterology 1989; 97: 1229-35.

15 Thistle JL, May GR, Bender CE, Williams HJ, LeRoy AJ, Nelson PE, et al. Dissolution of cholesterol gallbladder stones by methyl tert-butyl ether administered by percutaneous transhepatic catheter. $N$ Engl f Med 1989; 320 633-9.
16 Ponchon T, Baroud J, Pujol B, Valette PJ, Perrot D. Renal failure during dissolution of gallstones by methyl tert-butyl ether. Lancet 1988; i: 276-7.

17 DiPadova C, DiPadova F, Montorsi W, Tritapepe R. Methyl tert-butyl ether fails to dissolve retained radiolucent common bile duct stones. Gastroenterology 1986; 91: 1296300 .

18 Small DM. Cholesterol nucleation and growth in gallstone formation. $N$ Engl f Med 1980; 320: 1305-7.

19 LaMont JT, Turner BS, DiBenedetto D, Handin R, Schafer AI. Arachidonic acid stimulates mucin secretion in prairie dog gallbladder. Am $\mathcal{F}$ Physiol 1983; 245: 92-8.

20 Keating J, Noonan N, Healy M, O'Moore R, Corrigan OI, Keeling PWN. Lysolecithin production by bacterial phospholipase may cause gallstone nucleation. Gastroenterology 1989; 96: A252.

21 Neoptolemos JP, Hofmann AF, Moossa AR. Chemical treatment of stones in the biliary tree. Br F Surg 1986; 73: 515-24.

22 Summerfield JA. Review article: dissolution of gallstones in the biliary tree. Aliment Pharmacol Therap 1989; 3:211-21.

23 Hood K, Gleeson D, Ruppin DC, Dowling RH. Prevention of gallstone recurrence by non-steroidal anti-inflammatory drugs. Lancet 1988; ii: 1223-5.

24 Mok HYI, Bell GD, Dowling RH. Effect of different doses of chenodeoxycholic acid on bile lipid composition and on frequency of side-effects in patients with gallstones. Lancet 1974; ii: 253-7.

25 Iser JH, Murphy GM, Dowling RH. Speed of change in biliary lipids and bile acids with chenodeoxycholic acid is intermittent therapy feasible? Gut 1977; 18: 7-15.

26 Lanzini A, Jazrawi RP, Kupfer RM, Maudgal DP, Joseph AEA, Northfield TC. Gallstone recurrence after medical dissolution. An overestimated threat? $\mathcal{J}$ Hepatol 1986; 3: dissolutio.

27 O'Donnell LDJ, Heaton KW. Recurrence and re-recurrence of gallstones after medical dissolution - long term follow-up. Gut 1988; 29: 655-8.

28 Merril JR. Minimal trauma cholecystectomy. Ann Surg 1988; 54: $256-61$.

29 Dubois F, Icard P, Berthelot G, Levard H. Coelioscopic cholecystectomy: preliminary report of 36 cases. Ann Surg 1990; 211: 60-2.

30 Reddick EJ, Olsen DO. Laparoscopic laser cholecystectomy. Surg Endosc 1989; 3: 131-3.

31 Sackman $M$, Delius $M$, Sauerbruch, et al. Shock wave lithotripsy of gallbladder stones. The first 175 patients. lithotripsy of gallbladder stones.

32 Peine CJ, Petersen HJ, Williams CE, Bender CE, Patterson IE, Segura JW, et al. Extracorporeal shock-wave lithotripsy and methyl tert butyl ether for partially calcified gallstones. Gastroenterology 1988; 97: 1229-35. 